\title{
DE PERSONAGENS, PARTÍCULAS E DESTINO: O ENSAÍSMO DE GIACOMO DEBENEDETTI
}

\author{
Mateus Yuri Passos \\ mateus.passos@gmail.com
}

A primeira impressão de um leitor de Giacomo Debenedetti no século XXI é de que em seus ensaios parece faltar alguma coisa - palavras ou apostos, talvez. Não é raro encontrar em seus ensaios conceitos e nomes, especialmente de personagens, desfilando sem maiores explicações sobre sua origem e afiliação - Berardinelli (1999) diria que o ensaísta hipotetiza, com sua linguagem, a utopia de uma comunidade literária. Logo nas primeiras páginas de "Personaggi e destino", por exemplo, encontramos este trecho:

Lo sapiamo anche noi, che in nessuno di quei personaggi abbiamo scoperto la capacità di diventare, con la sua storia, un proverbio: un don Abbondio, un Julien Sorel, un padron 'Ntoni, una duchessa di Guermantes, un Raskolnikoff, un Tonio Kroeger, uno di quelli che batezzano le grandi congiunture e immagini con cui la vita si representa alle nostre vite (DEBENEDETTI, 1999, p.901)

Despontam aí personagens centrais de Os Noivos, O Vermelho e o Negro, Os Malavoglia, Em Busca do Tempo Perdido, Crime e Castigo $e$ Tonio Kröger, obras em sua maioria ainda presentes no imaginário 
literário, embora o editor de Il personaggio-uomo (DEBENEDETTI, 1998a) tenha inserido uma nota de rodapé para identifica-los, indício de que ao final do século passado o texto de 1947 já não encontraria tão facilmente leitores aptos a captar as referências, algumas delas talvez mais obscuras, como a que se encontra em "Commemorazione provvisoria del personaggio-uomo":

Anche il Simbolismo si mostrò puntualmente allergico alla scienza dei suoi tempi, mentre era corrivo alle aventure con la filosofia, tanto meglio se metafisica, cioè com richerche mentali, intelettuali di índole umanistica. La vera questione e conflito delle 'due culture' era forse più pertinente nei tempi romantici o simbolisti che nel nostro (DEBENEDETTI, 1998a, p.14).

Nesse caso, o ensaísta faz menção a um atrito fronteiriço, um choque entre placas tectônicas identificado em 1959, no ensaio As duas culturas, pelo físico e romancista inglês Charles Percy Snow: um abismo crescente entre a cultura humanista, das ciências sociais, das artes, e a das ciências "duras", exatas, tecnológicas. Essencialmente rivais, separadas inclusive fisicamente, em diferentes regiões de uma mesma cidade, por exemplo, ou em diferentes áreas de uma universidade, as duas facções não manteriam relações amistosas e seriam mesmo incapazes de se compreender mutuamente, raciocinando de formas completamente díspares. Snow lamentou uma rala representação das ciências naturais e tecnológicas nas artes e comunicação (ao contrário do que, em sua avaliação, ocorria na União Soviética de então) e na consequente baixa "alfabetização científica", com o desconhecimento, pela população em geral, de conceitos que seriam básicos para os cientistas:

Tanto quanto os surdos, eles não sabem o que estão perdendo. Sorriem com um desdém compassivo diante da informação sobre cientistas que nunca leram uma obra importante da literatura inglesa. Rejeitam-nos, tachando-os de especialistas ignorantes. No entanto, sua própria ignorância e sua própria especialização são tão surpreendentes quanto as deles. Muitas vezes estive presente em reuniões de pessoas que, pelos padrões da cultura tradicional, são tidas por altamente cultas, e que, com considerável satisfação, expressaram a sua incredulidade quanto à falta de instrução dos cientistas. Uma ou duas vezes fui provocado e perguntei quantos deles poderiam descrever a Segunda Lei da Termodinâmica. A resposta foi fria: também foi negativa. No entanto, eu estava perguntando algo que equivale em termos científicos a: Você já leu uma obra de Shakespeare? Acredito que, se tivesse feito uma pergunta mais simples, como, por exemplo: o que você entende por massa, que em o equivalente científico de dizer: Você sabe ler?, não mais do que uma em dez dessas pessoas altamente cultas teria sentido que estávamos falando a mesma língua. Desse modo o grande edifício da física moderna cresce, e a maioria dos 
homens mais inteligentes do mundo ocidental tem tanto conhecimento sobre ele quanto seus ancestrais neolíticos. (SNOW, 1995, p.32-33)

Snow defende que um maior conhecimento da ciência, e sua reconciliação com a cultura em geral, seria essencial para favorecê-la, em uma perspectiva essencialmente desenvolvimentista: conceitos científicos deveriam ser mais bem disseminados para alavancar o crescimento econômico. Embora acuse também os cientistas de isolarem ou ignorarem os homens de letras, seu ponto de vista pende mais para uma defesa das áreas tecnológicas e exatas e da incorporação de seus conceitos e feitos pela cultura em geral - união que cria ser factível entre o Renascimento e o Iluminismo -, em nível semelhante ao das obras de fruição estética. A polêmica que se seguiu o fez rever em parte suas afirmações em "Uma segunda leitura".

Comentaremos posteriormente as implicações maiores do comentário de Debenedetti sobre a menor pertinência dessa acusação em meados do século XX; por enquanto, apenas destacaremos dois aspectos que a referência levanta: em primeiro lugar, no texto de Snow, o diagnóstico de algo que só se intensificou nas décadas seguintes - a tendência à hiperespecialização, que viria a criar abismos e guetos dentro de cada área de pesquisa, tanto humanista quanto natural ou tecnológica; em segundo, certa negação disso, em parte responsável pela refutação de Snow por Debenedetti, numa das marcas do ensaísta italiano: a constante menção a nomes e eventos extraliterários que, imaginamos, seriam legíveis a seus contemporâneos: à teoria quântica de Planck, à relativística einsteiniana e ao princípio de incerteza de Heisenberg - posteriormente incorporada à "Commemorazione provvisoria del personaggio-uomo" -, o sistema heliocêntrico de Copérnico, às investigações neuropsiquiátricas sobre histeria, à teoria da História de Vico, à sinalização de Darwin para a etologia, todas em Il Romanzo del Novecento (ver DEBENEDETTI, 1998b, respectivamente p.3, p.425-426, p. 465, p.471, p.493, p.693). O procedimento, que hoje soaria como abertura de janelas para outras culturas, no ensaísmo de Debenedetti denota acima de tudo uma forte integração entre esses campos, mesmo 200 anos após a polêmica entre Hobbes e Boyle que teria começado a separá-los (SHAPIN e SCHAFFER, 1985).

Parcialmente responsável por isso é a formação de Debenedetti, antes que não-especialista, um multiespecialista: de família judia, nascido em 26 de junho de 1901 em Biella (capital da província de Piemonte) e morto em 29 de janeiro de 1967, aos 17 anos matriculou-se no curso de Engenharia Mecânica no Instituto Politécnico de Turim. Durante o curso, escreve 
peças teatrais e seu primeiro estudo critico, sobre Dante. Abandonará a engenharia em 1920 para graduar-se em Direito em 1922 - Berardinelli (2008) aponta para a forte presença de jargão jurídico em suas obras; $\mathrm{O}$ período será decisivo em sua vida, com a leitura intensiva de literatura, especialmente italiana e francesa, e a assídua frequentação do teatro de ópera local, onde o contato com os dramas musicais wagnerianos terão importante papel formativo (GERVASI, 2009). A leitura de um ensaio de Renato Serra o leva a decidir-se pelo ofício literário e a publicar pela primeira vez, em dezembro de 1921, no jornal Il Segnalibro, um texto crítico, sobre o poema "Il libro del collare" de Guido Pereyra. No ano seguinte, logo após a graduação em Direito, matricula-se na Faculdade de Letras e Filosofia, ainda em Turim, cujo curso concluirá apenas dali a cinco anos: nesse ínterim, dá início a um constante trabalho crítico, tendo como marco a fundação da revista Primo Tempo, em maio de 1922, que sustentará do próprio bolso por dez números, até maio do ano seguinte. Ali, já escreve sobre Il Canzionere, de Umberto Saba, e sobre a obra crítica de Benedetto Croce e Carlo Michelstaedler. Após o encerramento da publicação, começa a colaborar com outras - dentre elas Il Baretti, Quindicinale, Pegaso, Ambroisiano, Rassegna musicale, Fronte, Orizzonte Italico -, e a atuar como conferencista sobre literatura. Ainda em 1923 vê publicada, no número 11/12 de Il Convegno, sua primeira obra de ficção, a novela "Amedeo", compilada em Amedeo e altri racconti dali a três anos. Inspirada pela biografia de Mozart por Stendhal e permeada por um "tom Proust", a obra não terá um acolhimento positivo pelos pares de Debenedetti, especialmente por uma peculiar configuração reflexiva que a fará assemelhar-se ao ensaio, recebendo a alcunha de "racconto critico" (GERVASI, 2009) ou mesmo de ensaio crítico (MOOSBRUGGER, s/d). No futuro, o autor se aventuraria novamente pelas sendas ficção, mas pouco, gestando apenas mais dois volumes - Otto ebrei em 1944 e 16 ottobre 1943 no ano seguinte. Ao longo dos anos 1920, conforme sua ensaística toma corpo, também ela assume caráter literário e suas produções serão consideradas "racconti critici" (BERARDINELLI, 2008), em parte por conta do gosto crescente do crítico pela inserção de anedotas ligadas aos autores comentados, ou mesmo seus personagens. Décadas depois, a "literariedade" alça outro patamar na "Radiorecita su 'Jean Santeuil”, transmitida pela RAI em 1 de outubro de 1952 e publicada na terceira compilação de seus ensaios críticos, em 1959 - Berardinelli (1999) nota que várias de suas produções ensaísticas, derivam de conferências e outras formas de comunicação oral. 
DONNA Il guaio è che, coi sospetti, si sa come si comincia e non come si finisce. Qualcuno ha supposto che il coordinatore o ricucitore de Fallois abbia fatto anche il rammendatore: restaurando, costruendo qualche ponte: mettendo insomme qualche piccola protesi, come direbbero i dentisti.

CRITICO (divertito) Questa sarebbe impagabile! Si prenderebbe volentieri il biglietto per assistere a uno dei più clamorosi spettacoli della letteratura. Proust era un pasticheur sbalorditivo: un rifacitore di stili, da confondere qualunque intenditore...

DONNA C'è chi ha esclamato: "Viene vergogna di scrivere", dopo aver visto qualcuna delle abbagliantini contraffazioni e mistificazioni stilistiche combinate da Proust.

CRITICO ... E adesso proprio a lui, Proust, sarebbe stata resa la pariglia. A pasticheur, pasticheur e mezzo. Senza contare che l'imitatore sarebbe stato che più abile del maestro: capace di rifare un Proust coi tratti ancore incerti, già tutto lui e non ancora lui. Come un pittore che, guardando un adulto, riuscisse a fargli il ritratto di quand'era adolescente.

(Dal sottofondo, qualche battuta, alacre e sorniona, dell'Apprenti sorcier di Dukas)

PUBBLICO E va bene: diamolo per vero, questo Santeuil. Ma prima che ci diciate come esso ritocca la figura di Proust, diteci almeno che cosa racconta. CRITICO Semplicissimo. Basterebbe che il tecnico in cabina ci facesse riascoltare il nostro dialogo, da dove abbiamo cominciato a ricapitolare la biografia di Proust. Il Jean Santeuil racconta, per filo e per segno, la prima parte di quella biografia: i capitoli che concernono il tempo perduto.

DONNA È straordinario come i grandi artisti lavorino in economia. Chi legge la Ricerca, suppone un Proust inesauribile. E che soltanto raggioni di misura possano mettere un freno a quella sua portentosa improvvisazione, subito condensata in poesia. (DEBENEDETTI, 1999, p.966-967)

Debruçando-se sobre o Jean Santeuil de Marcel Proust, o ensaio radiofônico assume uma composição dialógica, encenando um encontro entre pontos de vista contrastantes a respeito do romance evidenciando, de forma mais radical, algo já característico de seu estilo ensaístico, que "non è descritivo e analitico, è speculativo e dialogico" (BERADINELLI, 2008, p.136) -; exemplifica também uma constante na obra debenedettiana: o forte interesse por Proust.

Há ainda que se mencionar alguns fatores biográficos que pesam em sua atuação literária e social. Em 1929, ano em que sua primeira coletânea de ensaios é publicada, torna-se colaborador da Società Cines, trabalhando com a tradução de filmes estrangeiros, na qual ajuda a introduzir duas importantes mudanças: a passagem dos filmes mudos para os sonoros - o que implica uma técnica diferenciada de legendagem - e a introdução da dublagem. A partir dessa experiência, passa a incorporar o repertório cinematográfico em seus ensaios - assim como 
prepara alguns especificamente voltados a filmes, tanto estrangeiros como italianos, variando seu interesse de Greta Garbo aos Irmãos Marx.

O marxismo também tem papel importante em sua vida: nos últimos dias da era Mussolini, aos 43 anos, filia-se ao Partido Comunista Italiano; o ímpeto em manter-se fiel ao partido o leva a recusar convites para participar de publicações que considerava incompatíveis com o pensamento socialista; ainda assim, sua relação com os correligionários é turbulenta e constantemente Debenedetti estaria isolado dentro do grupo. O ativismo o levou a experimentar uma escrita militante para o jornal Meridiano de Roma em 1956, com o qual colaborava desde a década de 30, mas não encontra satisfação em uma abordagem desviante daquela que já praticava, que já continha sua marca, sua personalidade em suma, sua verdadeira militância, que possuía outra natureza: a análise e crítica dos rumos estéticos que o romance moderno tomava.

Igualmente conturbada seria sua trajetória como professor universitário, iniciada já à meia-idade, em 1950, na Universidade de Messina, onde leciona História Literária Italiana moderna e contemporânea até 1956. Posteriormente pleiteará vaga na Universidade de Roma, mas terá várias candidaturas recusadas; será admitido na Faculdade de Letras em 1958, quando também obtém livre-docência. Concomitantemente, colaborará com a editora Mondadori, na qual inicia uma edição das obras completas de James Joyce; Debenedetti verá publicados em vida apenas dois dos cinco volumes planejados.

Nos anos 40, submete-se a tratamento psicanalítico: o interesse pelos conceitos, mais que pelos procedimentos, o tornará um dos primeiros italianos a incorporar Freud e Jung à crítica; coerentemente a seu procedimento, porém, não se converte em crítico psicanalítico: os dois pensadores tornam-se apenas mais dois pontos em sua constelação de referências culturais: não é raro, inclusive, que dispense ironicamente seus postulados na discussão de obras literárias: para Berardinelli (1999), ele os trata como uma nova manifestação, com ares cientificizados, da religião; contudo, vez por outra levará em conta conceitos como o inconsciente coletivo (MIRISOLA, 2009). Em "Personaggi e destino", de 1947, chegará ao ponto de indagar se Freud - "um galantuomo dell'Ottocento, empírico e positivista” (DEBENEDETTI, 1998a, p.120) seria válido para pensar a literatura novecentista, povoada essencialmente por órfãos.

O desconforto, e simultaneamente o grande interesse pela literatura de seu tempo, serão os traços essenciais da produção de Debenedetti desde a segunda metade da década de 1920, tendo já consolidado seu ofício como crítico em revistas literárias. Duas grandes produções 
dessa proposição crítica são a coletânea ensaística Verticale del '37, que reúne textos curtos publicados no Meridiano de Roma entre dezembro de 1936 e agosto de 1937 - o caráter "vertical" dos ensaios, atipicamente direcionados cada um a uma obra específica publicada naquele intervalo, quase como resenhas, se dá pela escolha de um único aspecto a partir do qual os romances serão analisados em sua totalidade - e Il Romanzo del Novecento, compilação póstuma, vinda à luz em 1971, de cadernos de anotações dos anos 1960, compondo uma espécie de romance crítico sobre nomes como Joyce, Proust, Tozzi, Moravia, Pasternak, Kafka, Pirandello, Svevo e os ensaístas Carducci, Serra, De Sanctis, Croce, Cecchi e Borgese. Dentre todos os aspectos listados, a "vertical" ensaística de Debenedetti pode ser encontrada nas preocupações com a forma e o destino do romance; é aí que se encontra o caráter de moralista moderno que Berardinelli $(1999,2008)$ lhe atribui, preocupado em observar o comportamento da prosa contemporânea italiana, esperando que nela se manifestasse a grandeza das produções literárias oitocentistas que ainda não haviam vicejado em seu país. Ele encontrou no entanto obras que cada vez mais se esquivavam do romanesco; Dois de seus ensaios centrais, datados de 1947 e 1965, alertam para os riscos de danação, o ranger de dentes imbuído no que considerava perda do humano, ou ao menos extrapolação máxima dos limites do humano. Um dos poucos autores aprazíveis a Debenedetti é Svevo, que publica sua mais famosa obra, A consciência de Zeno, concomitantemente à iniciação do ensaísta: talvez sua prosa lhe agrade por ainda ser possível vislumbrar peripécias e conferir-lhes um sentido global:

La biografia di Zeno è la storia di tanti fallimenti sucessivi che poi, per un caso ironico, o per un cappriccio, la vita si incarica di rendere vantaggiosi. Zeno ë l'uomo che, non sapendo guarirsi con una semplice rinunzia dal vizio di fumare, arriva alla più grave rinuncia di farsi chiudere in una casa di cura (con tutte le comiche e paradossali conseguenze: corruzione della infermiera per avere sigarette, evasione notturna, sospetti sulla fedeltà della moglie che forse in quel momento lo tradirà col dottore). È l'uomo che conserva la sua prosperità economica, proprio perché è sempre deluso nei suoi disastrosi tentativi di fare affari. (DEBENEDETTI, 1999, p.434-435)

Biografia - homem, história. É essa a maior expectativa que Debenedetti tem frente ao novo romance italiano, e é a que mais será frustrada em seu percurso crítico, sobretudo no que diz respeito aos personagens e sua participação tortuosa na realidade ficcional que são postos a habitar. 
Peça central na produção debenedettiana, "Personaggi e destino" nasceu como conferência proferida em 1947 na Semana do Escritor, em Perugia, e ganhou suporte escrito apenas postumamente, em 1971, com a publicação da terceira e última coletânea de ensaios do autor. Talvez o grande peso da palavra-chave do ensaio só seja sentido naquela transmissão radiofônica sobre Jean Santeuil que seria concebida dali a cinco anos, numa curtíssima sentença proferida pela voz do Critico: "Um romance é sempre uma parábola do destino" (DEBENEDETTI, 1999, p.968). Ao menos é essa a impressão que lhe causam Dostoievski, Balzac, Stendhal, Verga, Manzoni, os pais literários do século XIX, e os compositores operísticos Verdi e Wagner; mesmo autores do início do século XX, como Joyce, Proust e Mann, ainda parecem operar sob essa premissa: a fruição de suas obras é ainda agradável, segura. Citando Thibaudet, que confrontado com a afirmação de que o tabaco era a única das volúpias modernas acresceu à lista também a leitura dos romances, e Larbaud, que classificava o ato de ler como "vício impune", assinala a angústia do leitor contemporâneo devido ao tormento de pecado proporcionado pela épica moderna: os personagens que acompanha são ao mesmo tempo familiares e estranhos, conhecidos e ausentes, cujo crescimento e trajetória são difíceis de acompanhar como algo linear e progressivo - também são eles próprios agredidos pelo romancista e pelo romance: "Camminano sul pianeta Terra, eppure la forza di gravità che li tiene attacati sembra emanare dal suolo di um altro pianeta" (DEBENEDETTI, 1998a, p.106). Mesmo o diálogo, a confiança, a confidência entre personagens parece dificultada, ou impossível; o "destino" que guiava os grandes personagens nos grandes romances aqui se divorcia do indivíduo.

Para demarcar o abismo entre o novo momento literário e o precedente, Debenedetti lança mão da categorização - em contraposição, porém, às classificações do romance que considerava infindáveis, aponta apenas dois modos de composição que tipificam a mudança: épica da realidade e épica da existência:

Nella prima noi vediamo il personaggio muoversi in mezzo a un mondo con cui c'è ancora la possibilità di un'intesa reciproca. In quest'epica della realtà il personaggio è ancora assistito da qualche cosa, se non altro dalla fiducia in un collegamento tra sé e il mondo. Quello che gli succede, si produrrà dunque come qualche cosa di spiegabile. Nell'epica dell'esistenza, il personaggio è abbandonato da tutto, in mezzo a un mondo anch'esso abbandonato da tutto, 
e tra i due non è possibilide l'intesa, visto che si presentano l'uno all'altro come assurdi. Il mondo ha cessato di rispondere al personaggio; ciò che succede a costui apparirà quindi gratuito. (DEBENEDETTI, 1998a, p.107)

Desse modo, o pacto do destino, que desembocava em grandes narrativas e grandes personagens, perde o passo e surge um meio de cultura em que não poderão projetar-se em movimentos externos, somente internos. E é curioso que, ao mencionar os pontos de costura entre uma e outra espécie literária, dois dos grandes autores modernos cuja obra se caracteriza, para nós, pela ruptura, pela introdução de diversos procedimentos novos, são de certa forma "amansados" pelo ensaísta frente à literatura introduzida a partir da década de 1920 talvez por afiliá-los ao Simbolismo, assim como Edmund Wilson, crítico que admira. Joyce, visto como responsável por uma "domesticação do personagem", por reduzir no Ulisses seu campo de ação no mundo e interiorizá-lo, teria como válvula de escape o mecanismo de identificação com a Odisséia - em vez da redução dos personagens e eventos épicos a proporções domésticas, mesquinhas, Debenedetti vê nesse procedimento o efeito de homens comuns terem suas dimensões expandidas ao infinito ao se ligarem a suas contrapartes mitológicas: em vez de sintomas iniciais da crise do personagem, um sagaz acomodamento, mesmo provisório, a ela, conferindo aos protagonistas um destino escrito não por ele, mas por Homero. Proust, por sua vez, teria como grande movimento a projeção, sobre o passado, das opiniões do presente - ao fazê-lo, tece e retece aos olhos do leitor seu caráter, seu comportamento, sua caracterização cambiante dos personagens que ganham o direito de viverem como são e terem a cada momento de sua vida uma identidade reinventada; ainda assim, apenas uma, construída a partir de um percurso coerente.

Ao instituir a revolta do personagem - com os Seis que saem em busca de um autor e fazem críticas aos atores que os interpretam, ao diretor que os coordena; com as angústias de Vitangelo Moscarda ao dar-se conta da miríade de identidades que possui, uma para cada pessoa que conhece, e das expectativas que elas criam em torno de seu comportamento, e tentar frustrá-las, fazê-las repensar como o vêem; com Lina/Julia, que assume ao mesmo tempo, para a "mãe" e o "marido", duas identidades contraditórias, que se anulariam mutuamente, e abrindo mão de afirmar se uma delas, ou uma hipotética terceira, é genuína -, Pirandello abriria as portas do inferno.

Kafka, pelas distorções causadas pelo senso de culpa e inferioridade de seus protagonistas - um deles, o agrimensor do Castelo, reduzido a apenas uma letra como identificação -, também sinalizaria as mudanças, 
a transição para a épica da existência, embora seu meio de cultura ainda fosse o paradigma anterior:

\begin{abstract}
Naturale che l'impiegato Samsa si svegli una mattina trasformato in quel gigantesco millepiedi: questa è la logica pertinente al suo senso di inferiorità, tanto per dire, e alla sua angoscia di sentirsi estraneo agli altri e ripugnante. Naturale che l'impiegato di banca indicato con la lettera K. si svegli una mattina e trovi gli uomini della Polizia, venuti a prenderlo per un processo, che nessun codice autorizza e nessun reato giustifica: que è la logica del suo senso di colpa, tanto per dire. E questa è ancora un'epica della realtà, sebene tanto mutata da quella che ci siamo lasciati dietro le spalle: anche Kafka, a suo modo, e forse più rigorosamente di tutti, osserva la vita: quella vita autonoma dei conflitti e delle angosce tutte intere attaccate alla loro preda. (DEBENEDETTI, 1998a, p.117)
\end{abstract}

A trajetória desenhada pela narração de Kafka chegaria ao espaço ocupado pela épica da existência, já desprovido da Nekuia homérica, do ponto de virada, de resolução; mas não ficaria completamente fechada e acomodada na nova forma composicional, apontando para as vertigens, as distorções do que se acreditava ser real.

É o pai, a figura de autoridade freudiana a grande ausência que marca o cenário da épica da existência; embora a psicanálise o rotulasse como castrador, era sua a função de assegurar o destino dos filhos, ainda que esse fosse o da revolta contra os genitores - para o ensaísta, os modelos do grande romance do século XIX tinham função análoga à paterna, lançando simultaneamente leis a serem quebradas e um terreno seguro para os romancistas de sucessivas gerações. O mundo de Kafka, dos personagens sem autor, é o de órfãos, filhos que perdem os pais e de certa forma ainda querem voltar a eles - os castigados personagens do novo romance, do anti-romance, nem poderão ter essa pretensão. E, para o ensaísta, esses são órfãos que deveriam reencontrar o caminho de casa - e, assim, realizar o grande romance ainda no século XX, se possível na Itália.

Uma interessante ponderação é de que se Zola, esteta máximo da realidade, criticado por Debenedetti por assumir uma posição pseudocientífica, contrária à criação, pudesse ter lido Kafka, talvez revisse muitos de seus conceitos - seria como se Euclides fosse posto frente a frente com um tratado de geometria do hiperespaço, especialmente no que tocaria ao quanto os modelos antigos ainda pareceriam viáveis frente aos novos. Da mesma forma, a psicanálise freudiana pareceria mais adequada ao ambiente e às personagens oitocentistas.

$\mathrm{O}$ ponto mais angustiante, porém, é que, frente às novas rotas, a manutenção da estética da realidade - no romance e sobretudo no 
cinema norte-americano - pareceria extremamente ingênua. O ritmo cinemático de Paesi tuoi, de Pavese, com ares estrangeiros, de nãopertencimento, e o procedimento de "sfogare nel surreale la carica che il linguaggio aveva adensato nel protagonista" (DEBENEDETTI, 1998a, p.108) de Conversazione in Sicilia, de Vittorini, resultariam em experimentos falhados. O caminho da orfandade parece não ter volta.

\section{III}

Proferido como conferência na Mostra de Cinema de Veneza, em 1965, e publicado no número 16o da revista Paragone em dezembro do mesmo ano, "Commemorazione provvisoria del personaggio-uomo" é dessas produções que de certa forma sintetizam a obra de uma vida. Estão ali os traços elementares da ensaística debenedettiana: o dialogismo, o elogio de Proust, as referências literárias, científicas e cinematográficas, a angústia (intensificada) frente ao romance novecentista e a psicanálise - aqui representada por uma singela menção a Jung e seu conceito de persona, de máscara, comparado ao "átomo em liberdade" que nos monólogos interiores de Joyce expressaria a relação do personagem com seu trabalho, família, sociedade, consigo próprio, de forma isolada, condensada, sem um todo totalizante que caracterizasse Bloom definitivamente. Não há sinal de Freud, talvez porque, como sinalizado em 1947, sua teoria não pertença ao mundo sobre o qual Debenedetti discorre aqui.

A arquitetura do ensaio causa grande estranhamento, em especial porque aquele que deveria ser o tópico principal, o protagonista do texto, está presente apenas como lembrança nostálgica, ou como assombração. Ele é apresentado logo à primeira página, mas não o veremos mais no restante da obra:

\footnotetext{
Chiamo personaggio-uomo quell'alter-ego, nemico o vicario, che in decine di migilaia di esemplari tutti diversi tra loro, ci viene encontro daí romanzi e adesso anche dai film. Si disse che la sua professione sia quella di responderci, ma molto più spesso siamo noi i citati a respondergli. Se gli chiediamo di farsi conoscere, come capita coi poliziotti in borghese, gira il risvolto dela giubba, esibisce la placa dove sta scrittta la più capitale dele sue funzioni che è insieme il suo motto araldico: si tratta anche di te. (DEBENEDETTI, 1998a, p.11)
}

Alguém que responde ao leitor, mas a quem o leitor igualmente responde, com quem é possível identificar-se: o personagem-homem é, digamos, qualquer personagem da grande literatura ocidental, da 
Ilíada ao Rougon-Macquart, que se exibe completo, coerente, ainda que seu destino o faça transformar-se, amadurecer. A impressão que Debenedetti causa, no entanto, é de que ele está morto: na sequência, tratará das metamorfoses do personagem de ficção no início do século XX, novamente nas mãos de Proust, Joyce e Kafka, seguidos de Ionesco e Beckett, e sua transformação em anti-personagem, aparentemente a regra a ser seguida dali por diante - tônica muito próxima daquela, novamente em "Personaggi e destino", que ditava a ingenuidade e impossibilidade de se retomar a épica da realidade -, conforme lemos nas duas frases que fecham o ensaio:

Mettendo da parte le teorie, la pratica si lascia intravedere il pericolo che stia nascendo o sia già nata un'arcadia dell'antipersonaggio. E allora, a chi votarsi se non al vecchio, ma ancora vegeto, solerte, servizievole personaggio-uomo?

(DEBENEDETTI, 1998a, p.49)

Desse modo, "Commemorazione provvisoria del personaggio-uomo" é essencialmente, como indica o título, um canto elegíaco, marcha fúnebre para uma - agora - impossibilidade literária. São os descendentes, substitutos, se não usurpadores do personagem-homem que povoam o texto, personagens cuja vida, nas palavras de Robbe-Grillet, dura tanto quanto a leitura de um romance ou a projeção de um filme (e não o extrapola, como nas grandes narrativas, no grande romance), e que já pareciam consolidar uma nova tradição composicional.

Outro aspecto curioso é a presença do cinema. Uma vez que o contexto original do trabalho era uma fala num festival cinematográfico, era de se esperar no ensaio uma presença mais firme da sétima arte. Falase dos anti-personagens de Antonioni, Godard, Robbe-Grillet, mas a incorporação dessa discussão tem caráter de apêndice e não corresponde a um quarto da totalidade do texto.

Um de seus pontos essenciais é a já mencionada referências às Duas culturas e à afirmação de que o contraste e a abertura de um abismo entre elas não estaria se intensificando, mas minguando - não como pretendia Snow, com a inserção de conteúdo científico, de conceitos, ambientes e personagens oriundos das investigações em ciências exatas e das realizações tecnológicas, mas de uma aproximação no comportamento de literatura e ciência, que procurariam transmitir o mesmo tipo de informação, ao observar e descrever aspectos e materiais da natureza, da experiência do mundo. Enquanto Kafka introduziria o princípio da incerteza, a incerteza quanto à verdade e à necessidade das coisas, dos fatos, a grande realização de Proust e Joyce seria a atomização 
do personagem, cuja homogeneidade e integralidade prévias seriam substituídas por pequenas unidades psicológicas ou figurativas.

O ensaísta ilustra a aproximação entre literatura e ciência com uma série de "diálogos imaginários" entre um romancista e um físico, identificados, como os derradeiros protagonistas dos romances de Kafka (e também como as variáveis e incógnitas de fórmulas e equações matemáticas) apenas por letras:

\begin{abstract}
(...) un immaginario dialogo sui rispettivi personaggi, tra un fisico e un romanziere degli anni Sessanta, rischierebbe di creare i più deplorevoli equivoci sui nomi degli interlocutori:

$\mathrm{X}$ - Il nuovo personaggio "crea una serie di contraddizioni con le idee classiche e col buonsenso, nato per l'appunto dalle esperienze sensoriali”.

Y - "L'aspetto un po'inconsueto di questo mondo... ci rivela al tempo stesso il carattere inconsueto del mondo che ci circonda: inconsueto, anch'esso, nella misura in cui ricusa di piegarsi alle nostre abitudini di apprendimento e al nostro ordine."

$\mathrm{X}$ - Tra i comportamenti dei nuovi personaggi e quelli dei loro predecessori si è creata una frattura che ci costringe a "compiere un vero sforzo dell'immaginazione per riuscire a stabilire un collegamento tra le nuove frontiere e il mondo ordinario". (DEBENEDETTI 1998a, p.31-32)
\end{abstract}

Diz Debenedetti que o último a falar é o físico; o que nos confunde, uma vez que é $\mathrm{X}$ quem trata de personagens e $\mathrm{Y}$ do aspecto insólito da realidade material; a estranheza aumenta posteriormente, quando os papéis de $\mathrm{X}$ e $\mathrm{Y}$ se invertem - engenhoso mecanismo para demonstrar seu argumento da proximidade e similaridade de comportamentos entre o cientista e o literato modernos.

O passo seguinte seria, como na física quântica, a exploração do mundo subatômico: semelhante a elétrons e prótons - felizmente ainda não se falava nos efêmeros quarks -, o personagem-partícula de Beckett, Ionesco e do Nouveau Roman segue suas leis internas, absolutamente inarticuláveis com o mundo material macroscópico, no qual se anulam, e com o qual não conseguiriam se relacionar - daí as ações incalculáveis no "teatro do absurdo" de Beckett e Ionesco. Debenedetti chega a indagar se a grande questão literária de seu momento é a incomunicabilidade do anti-personagem ou a personificação da incomunicabilidade neles condensada.

O ponto mais angustiante para Debenedetti talvez seja sua constatação de que apesar de o personagem não mais responder ao leitor (nem este e a ele), nem à sua realidade ficcional, frente à qual se anula, se esvai, o romance contemporâneo poderia ainda tocar e ser compreendido 
- mas jamais explicado. Situação que de certa forma não oferece vias de escape para a crítica.

\section{REFERÊNCIAS BIBLIOGRÁFICAS}

BERARDINELLI, Alfonso. La forma del saggio. 2. ed. Veneza: Marsilio Editori, 2008. . Giacomo Debenedetti, il libertino devoto. In: DEBENEDETTI, Giacomo. Saggi. Milão: Mondadori, 1999, p.xi-xlix.

. Ricerca, conversazione, insegnamento. Letteratura e arte. Disponível em: http://www.giacomodebenedetti.it/index.php?option=com content\&view= article\&id=31:ricerca-conversazione-insegnamento\&catid=7:il-novecento-didebenedetti\&Itemid=7 Acesso em: 13 nov. 2011.

DEBENEDETTI, Giacomo. Il personaggio-uomo. Milão: Garzanti, 1998a. . Il romanzo del novecento. Milão: Garzanti, $1998 \mathrm{~b}$. . Saggi. Milão: Mondadori, 1999.

GERVASI, Paolo. L'eresia dell'uomo. Giacomo Debenedetti: storia di un inizio, 1922-1934. 2009, 426 f. Tese (Doutorado em Língua e Literatura Italiana), Facoltà di Lettere e Filosofia, Università di Pisa, Pisa.

MIRISOLA, Beniamino. La critica come processo d'individuazione. Tessere junghiane nella saggistica di Giacomo Debenedetti. 2009. Tese (Doutorado em Ciências Humanas/Italianística), Università Ca' Foscari, Veneza.

MOOSBRUGGER, Hilarius. Giacomo Debenedetti: I 'Racconti critici'. Maremagnum. Disponível em: http://www.maremagnum.com/articoli/?p=492 Acesso em: 19 nov. 2011

SHAPIN, Steven; SCHAFFER, Simon. Leviathan and the air-pump: Hobbes, Boyle and the experimental life. Princeton: Princeton University Press, 1985.

SNOW, C. P. As duas culturas e uma segunda leitura. São Paulo: Edusp, 1995. 